\title{
O COMÉRCIO DE TERRAS E A EXTRAÇÃO DA RENDA FUNDIÁRIA URBANA EM CIDADES DO RIO GRANDE DO NORTE: UM ESTUDO DE CASO DAS CIDADES DE BOA SAÚDE, LAGOA SALGADA E SERRA CAIADA-RN
}

\author{
Francisco Aracildo de Moura \\ Doutorando em Geografia \\ Programa de Pós-graduação e Pesquisa em Geografia/UFRN \\ aracildomoura@yahoo.com.br \\ Ademir Araújo da Costa \\ Doutor em Geografia e Professor Permanente do PPGE/UFRN \\ Professor visitante do PPGEO/UERN \\ ojuarademir@gmail.com
}

José Erimar dos Santos

Doutor em Geografia e Professor Adjunto do Departamento de Ciências Humanas da UFERSA zerieval@gmail.com

\begin{abstract}
RESUMO
Esta pesquisa discute o parcelamento de terras a partir dos loteamentos existentes nas cidades de Boa Saúde, Lagoa Salgada e Serra Caiada no Rio Grande do Norte, onde o comércio de terras vem ocorrendo intensamente. Assim, buscamos compreender as motivações para que a terra venha sendo posta a venda por meio de lotes, o que tem impulsionado, principalmente, a extração da renda fundiária urbana nas cidades em tela. Nesse contexto, analisamos a terra enquanto provedora e sua função social para o povo até a aprovação da Lei de Terras aqui no Brasil, a qual reconfigura o modo de acesso à terra, colocando-a como produto. A terra, transformada em produto passível de uso e de troca, a posse desse bem, possibilita que o seu proprietário faça a extração das diferentes rendas: de monopólio, diferencial e absoluta, a depender das características existentes na terra posta no mercado. Observando as características dos loteamentos analisados em cada cidade, nos conduziu a compreensão de como vem se dando o processo de parcelamento e loteamento de terras em cidades potiguares.
\end{abstract}

Palavras-chave: Loteamentos. Terra. Renda da terra. Lei de terras.

\section{THE COMMERCE OF LAND AND THE EXTRACTION OF URBAN FOUNDRY INCOME IN CITIES OF RIO GRANDE DO NORTE: A CASE STUDY OF THE CITY OF BOA SAÚDE, LAGOA SALGADA E SERRA CAIADA-RN}

\begin{abstract}
This research discusses the parceling of land from the existing settlements in the cities of Boa Saúde, Lagoa Salgada and Serra Caiada in Rio Grande do Norte, where land trade has been occurring intensely. Thus, we seek to understand the motivations for the land to be put up for sale by means of lots, which has driven, mainly, the extraction of urban land rent in cities on canvas. In this context, we analyze the land as a provider and its social function for the people until the approval of the Land Law here in Brazil, which reconfigures the way of access to land, putting it as a product. The land, transformed into a product that can be used and exchanged, the possession of that good, allows the owner to extract the different incomes: monopoly, differential and absolute, depending on the characteristics of the land put on the market. Observing the characteristics of the subdivisions analyzed in each city, led us to understand how the process of land subdivision and land subdivision has taken place in local cities.
\end{abstract}

Keywords: Allotments. Earth. Income of the earth. Land law. 


\section{INTRODUÇÃO}

O Brasil é um país, ainda, em que as cidades retratam profundas desigualdades de condições de moradia e de acesso aos equipamentos e serviços urbanos, pois resultam de um sistema econômico e político centrado na apropriação desigual dos resultados do trabalho e das relações sociais. Levando em consideração essa marca impressa na paisagem, este trabalho tem como objetivo analisar o comércio de terras nas cidades de Boa Saúde, Lagoa Salgada e Serra Caiada no Rio Grande do Norte, localizadas na Microrregião do Agreste Potiguar (Mapa 1), identificando os mecanismos que os produzem mediante os interesses dos agentes do mercado imobiliário mediante apoio do poder público. Analisa o crescimento no mercado de terras nessas cidades a partir de loteamentos em áreas de expansão urbana, desmembradas pelo poder público local de áreas até então rurais. Para tanto, foram considerados três loteamentos, um em cada cidade, totalizando 684 lotes, de um total de mais de dois mil lotes à venda no mercado de terras local, na última década.

Figura 1 - Localização Geográfica da área de estudo (Boa Saúde/RN, Lagoa Salgada/RN e Serra Caiada/RN)

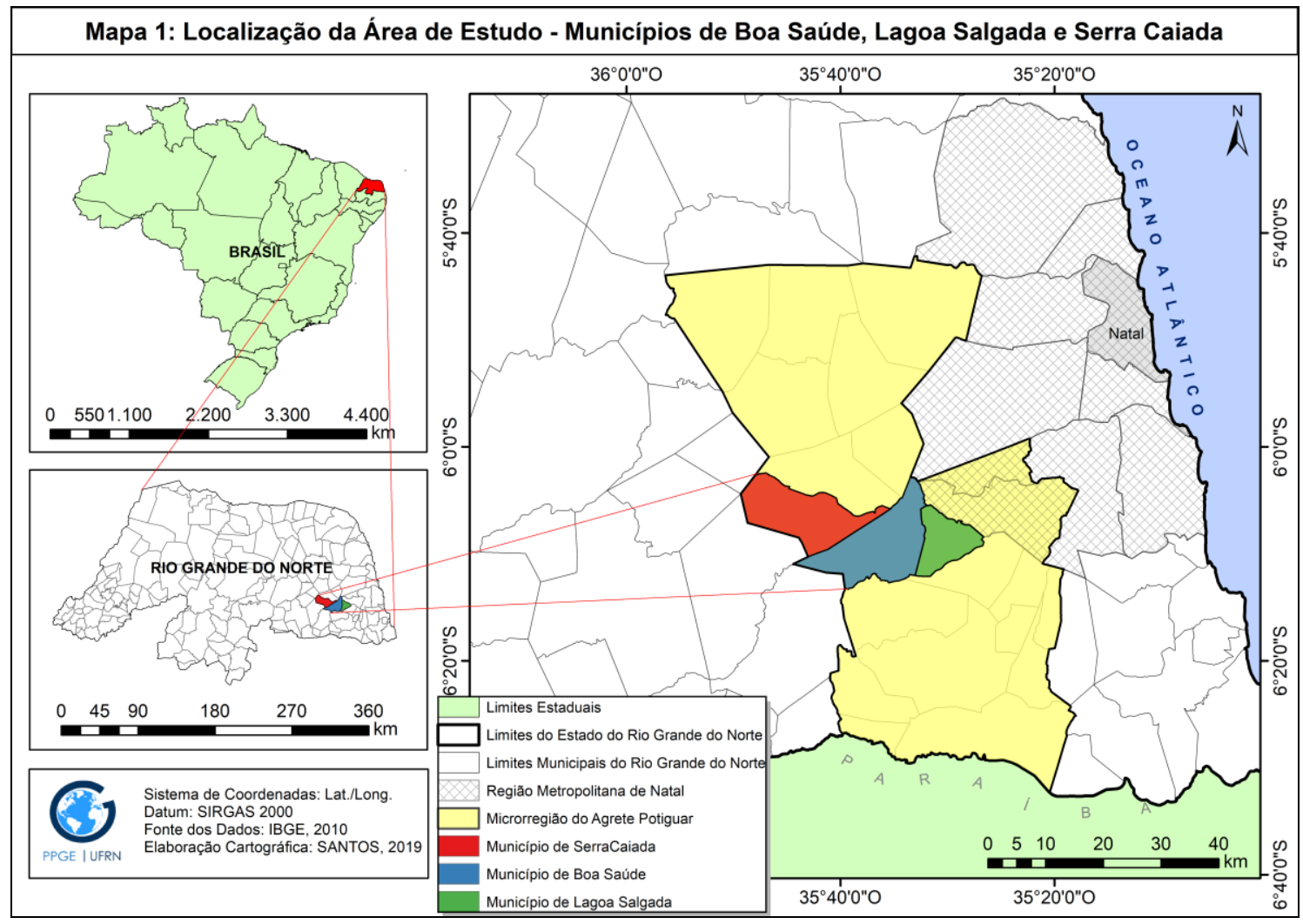

Fonte: IBGE (2010).

A área de estudo compreende as cidades de Boa Saúde, Lagoa Salgada e Serra Caiada, estando localizadas no entorno da Região Metropolitana de Natal (RMN) (Mapa 1), o que contribui para que muitas pessoas que residem na RMN procurem lotes de terras nessas cidades como investimentos e, até mesmo para construírem uma segunda moradia.

A escolha do tema tem como motivação o interesse pela compreensão da dinâmica presente nas ações destinadas à produção habitacional e sua relação com a ocupação e usos do espaço urbano nessas cidades. A terra urbana transformada em mercadoria é objeto de especulação para o controle privado e da valorização de investimentos públicos e privados, tendo sua origem, no Brasil, já há cinco séculos, conforme atesta Maricato (2001).

A abordagem do tema é desenvolvida a partir de um enfoque de aspectos históricos e dinâmica da paisagem envolvidos no processo de formação dessas cidades potiguares, além de análise

Caminhos de Geografia $\quad$ Uberlândia $\quad$ v. 20, n. $72 \quad$ Dez/2019 $\quad$ p. 345-359 Página 346


sobre o desenvolvimento do capitalismo e da urbanização nesse recorte espacial, tendo como tema central os loteamentos urbanos.

É importante ressaltar que a proliferação dos loteamentos nas referidas cidades se dar em virtude de que para os donos de terras, o loteamento se constitui numa forma "encontrada para realizarem a renda da terra obtendo sobrelucros com a sua venda" (MOURA, 2016, p. 46). Por outro lado, dada o aumento da população urbana nessas cidades em detrimento da rural, percebemos a existência de uma demanda que compra esses lotes para construir sua própria moradia. Portanto, "a terra enquanto mercadoria, ao ser colocada no mercado tem um preço, e é esse preço que possibilita o dono da terra realizar a extração fundiária urbana" (MOURA, 2016, p. 16).

Considerando o perfil socioeconômico dos municípios em tela, Boa Saúde conta com uma população de 9.011 habitantes, dos quais 3.243 residem na zona urbana, apresentando uma densidade demográfica de $48,13 \mathrm{hab} . / \mathrm{km}^{2}$ (IBGE 2010). O município tem como sua principal fonte de renda a agricultura de subsistência e transferências de renda do governo federal.

O município de Lagoa Salgada está a 52 quilômetros da cidade de Natal, conta com uma área de $79,330 \mathrm{~km}^{2}$ e uma população de 7.564 habitantes e, densidade demográfica de $95,35 \mathrm{hab} . / \mathrm{km}^{2}$. Aí, 5.005 pessoas residem na zona urbana. A economia do município está assentada na agricultura, no comércio, nos serviços e nas transferências de renda do governo federal. Os principais produtos da economia agrícola do município são a mandioca e a castanha de caju que também estão presentes em Boa Saúde e Serra Caiada. Outro setor da economia que apresenta bastante expressividade é a produção de farinha e fécula de mandioca. O destaque maior ocorre para a Fábrica Prata Fina existente na comunidade do Exú, figurando entre as mais modernas do Estado, pelo elevado nível de tecnologia empregada (MOURA, 2014, 2016).

O município de Serra Caiada compreende uma área de $167,348 \mathrm{~km}^{2}$, conta com uma população de 8.768 habitantes, da qual 5.313 habitantes residem na zona urbana IBGE (2010), apresentando uma densidade demográfica de $52,39 \mathrm{hab} / \mathrm{km}^{2}$. A sua economia é predominantemente agrícola, subdividida entre a agricultura e a pecuária, apesar de apresentar um crescimento considerável do seu comércio, respaldado por uma concorrida feira que ocorre aos domingos e as transferências de renda do governo federal.

No entanto, nos últimos anos estas cidades vêm passando por mudanças em sua estruturação urbana e se inserindo no processo de industrialização. De acordo com o IBGE (2018), no ano de 2016, Boa Saúde contava com 30 estabelecimentos industriais, sendo responsável por manter 324 pessoas ocupadas; para o mesmo ano Lagoa Salgada contava com 52 unidades industriais as quais eram responsáveis pela ocupação de 362 pessoas no município; já Serra Caiada, no mesmo período contabilizava 61 indústrias, empregando 625 pessoas. Destaque-se que a inserção das atividades industriais nessas cidades, não só estimulam a atividade comercial, como trazem uma nova dinâmica para o viver urbano.

Nesse contexto, mesmo nas pequenas cidades a luta pelo direito de ter a posse da terra é histórica, atravessa diferentes períodos e chegou aos dias atuais como um problema que ainda requer solução e atenção por parte dos governantes. Hoje, uma das opções encontradas por aqueles que buscam adquirir uma parcela de terra para morar ou deixar como reserva especulativa, pode ser a aquisição de um ou mais lotes em áreas onde esteja ocorrendo o processo de parcelamento da terra.

Considerando que a terra tem como função social possibilitar a moradia e sobrevivência do homem num dado lugar, para nossa análise, dentre os loteamentos existentes em cada cidade, selecionamos aquele que apresentou maior infraestrutura como elemento impulsionador para a venda dos lotes, o que o diferencia dentre os demais. Destaque-se que, durante a nossa pesquisa as três cidades contavam com 19 loteamentos (empreendimentos), os quais contabilizavam 2.072 lotes de terras colocados, simultaneamente, à venda no mercado.

\section{O PREÇO DA TERRA}

Baseando-se em Martins (1979), Moura (2016) destaca que, no Brasil, a busca pela terra remonta o período da "descoberta" do país pelos portugueses e se deu entre nativos e europeus que tentaram a quaisquer custos colonizar a nova terra. No Brasil Imperial essa luta vai ser reforçada quando da aprovação da Lei no 601 de 18 de setembro de 1850 (Lei de Terras),

$\begin{array}{lllll}\text { Caminhos de Geografia } & \text { Uberlândia } & \text { v. 20, n. } 72 & \text { Dez/2019 } & \text { p. 345-359 Página } 347\end{array}$


quando o governo brasileiro passa a imprimir um valor monetário como pré-requisito a ser cobrado àqueles que desejassem acesso às terras existentes no país. Destaque-se que até então as terras do Império não eram comercializadas e o direito de uso se dava por meio de doação, principalmente, a pessoas que exerciam cargos ou dispunham de algum prestígio junto à administração do Império.

A terra que antes era de livre acesso para todos que necessitassem utilizá-la, passa a ser propriedade privada do Estado com comércio legalizado em todo território. Neste sentido, Martins (1979, p. 20), lembra que "sendo a terra um fator natural, sem valor porque não é o resultado do trabalho humano, teoricamente não deveria ter preço". Logo, o valor da terra perpassa pelo valor de uso. Por ser um bem natural e não reproduzível pelo trabalho humano, não deveria ter preço, pois essa medida por parte do império fez aumentar as desigualdades entre proprietários e não proprietários de terras (MOURA, 2016).

Com isso, surge em terras brasileiras uma classe de pessoas ainda mais pobre, os ex-escravos (MARTINS, 1979). Para quem detém sua posse a terra representa poder. Segundo Martins (1979, p. 24-25), "[...] a ocupação da terra obedecia a dois caminhos distintos: de um lado o pequeno lavrador que ocupava terras presumivelmente devolutas; de outro, o grande fazendeiro que, por via legal, obtinha cartas de sesmarias [...]".

As desigualdades são reforçadas quando a terra passa a ter valor de mercado, sendo transformada em produto comercializável. Antes da Lei de Terras, o pequeno lavrador e o grande fazendeiro conviviam, em alguns casos, no mesmo espaço. O primeiro usava a terra, mas não tinha sua posse, a terra era um meio encontrado para retirar o sustento da família. Já o fazendeiro, detinha a posse através da concessão de sesmaria e mesmo sem valor comercial a terra representava status, poder e influência.

Diante disso, a terra recebe nova condição e sua função não mais reflete o social, da moradia, de fixação do homem num dado lugar onde pudesse extrair o sustento e manutenção a sua sobrevivência. Como mercadoria, sua aquisição só é possível mediante a troca pelo dinheiro. Neste sentido, compreende-se que a realização da renda da terra para o mercado dar-se-á a partir do momento em que o uso e a troca desta passaram a ser um negócio rentável.

\section{A LEI DE TERRAS E A EXTRAÇÃO DA RENDA FUNDIÁRIA URBANA}

Com base nos escritos de Moura (2016), com a promulgação da Lei de Terras, esta assume a condição de mercadoria. Anteriormente, o uso da terra era por concessões, financeiramente o seu valor econômico era nulo ou pouco representativo para seus "proprietários", pois, o comércio de terras era praticamente inexistente.

Em 1882, a Associação Comercial de Santos estimava que, do valor de uma fazenda de café, uns $20 \%$ poderiam corresponder à avaliação da terra. [...]. Mais valiosos que a terra eram os escravos. Isso porque antes do seu aparecimento ali o valor venal da terra era nulo. Assim, a fazenda nada mais representava senão o trabalho escravo acumulado (MARTINS, 1979, p. 25).

Com a referida lei, as terras não ganharam valor comercial de imediato, pois, quase três décadas após sua promulgação, o valor que a terra representava na fazenda ainda era muito baixo se comparado a outros "bens" da propriedade, como o escravo. A terra que representa o substrato e dá a condição real para que haja qualquer produção, fixação e formação de uma identidade com o lugar, parece não representar as necessidades primeiras de seus proprietários, uma vez que, independente de sua extensão, quase sempre seu valor era posto como inferior a um quarto do valor real representado pela fazenda (MARTINS, 1979). Sobre o valor da fazenda, Martins (1979, p. 26) afirma que, "de fato, a terra sem trabalhadores nada representava em termos econômicos; enquanto isso, independente da terra, o trabalhador era um bem precioso".

A força de trabalho realizada pelo escravo era, de fato, o bem mais precioso, pois era o que impulsionava a geração de renda e, consequentemente, o acúmulo de capital para o proprietário. Como o trabalho era exclusivamente manual, o escravo não representava apenas o maior valor da propriedade, como também, sua posse era sinônimo de status para o fazendeiro. No mesmo período,

A renda capitalizada no escravo transformava-se em renda territorial capitalizada: num regime de terras livres, o trabalho tinha que ser cativo; a terra

$\begin{array}{lllll}\text { Caminhos de Geografia } & \text { Uberlândia } & \text { v. 20, n. } 72 & \text { Dez/2019 } & \text { p. 345-359 Página } 348\end{array}$


tinha que ser cativa. [...] A propriedade do escravo se transfigura em propriedade da terra como meio para extorquir trabalho e não para extorquir a renda (MARTINS, 1979, p. 32).

No Brasil comércio de terras passa a ser incorporado ao mercado financeiro a partir de um processo decadente que perdurou durante séculos, a base e o sustentáculo da economia vigente à época, ou seja, o trabalho escravo. Enquanto o trabalho escravo sustentou a economia, a terra era um bem com baixo valor, tendo em vista que a compra de escravo era um privilégio para poucos, por ser uma mercadoria cara e hereditária. Quando o trabalho já não mais é executado pelo escravo e ele passa a ser livre, a terra passa a ser mercadoria, seu acesso só é possível mediante troca por dinheiro (MARTINS, 1979).

A renda da terra, até então, se realizava apenas pelo que ali se produzia, como também, pela força de trabalho do escravo sobre a terra. Assim, a terra apresenta valores diferenciados, considerando sua localização e função, pois, se é uma terra rural, esta terá um valor; se faz parte ou localiza-se em uma área de expansão urbana, o valor será outro e, ganha um diferencial a mais quando esta faz parte de uma cidade ou está dentro de zonas em expansão de uma mancha urbana.

Esse diferencial não é apenas por fazer parte do urbano, mas, o diferencial se dá, principalmente, porque o solo urbano é escasso e nem todos podem usufruir desse tipo de terra. Considerando os benefícios, comodidades, proximidade a equipamentos públicos, presença de meios de transportes e redes de comunicação, abastecimento de água e energia mais eficaz, juntamente com a escassez, estes itens encarecem ainda mais o preço da terra na cidade.

Com relação aos loteamentos, de acordo com o comportamento do mercado de terras, percebemos que quanto mais bem-dotado de equipamentos e infraestrutura tiverem esses empreendimentos, maior será a reserva financeira que o cidadão deve dispor para adquirir um lote, vez que essas características diferenciam a área a ser vendida e, consequentemente, inflaciona o valor do lote. A infraestrutura existente no loteamento tem um peso considerável para o comprador que adquire o lote com o intuito de construir a moradia, pois é um item que dá condição de habitabilidade ao empreendimento. Com visão de mercado, proprietários e empresas que comercializam e vendem terras de áreas urbanas impulsionam a realização da renda da terra.

A terra tem um valor de uso, mas, é antes de tudo, substrato de fixação do homem em um dado lugar no espaço. A partir do uso que se dá a terra, esta, ganha novos arranjos e se diferencia quanto a valores a serem pagos para que esta seja usufruída. De acordo com Harvey (2013, p. 435-436; destaque do autor) "[...] a terra serve não apenas como um meio de produção, mas também como uma 'fundação, como um lugar e um espaço que proporciona uma base de operações' - o espaço é requerido como um elemento de toda produção e atividade humana". Por ser a base onde se processam as operações, o espaço onde tudo acontece, produz e se reproduz, estipula-se um valor a ser pago para fazer uso de uma parcela de terra e dos bens e serviços ali disponíveis.

A terra se configura em valor para o proprietário que realiza sua renda pelo fato de ter para si a posse e o direito de uso. Harvey (2013, p. 437) diz que "a posse da propriedade privada da terra confere poder exclusivo a pessoas privadas sobre algumas porções do globo". Há um interesse que perpassa o simples fato de transformar a terra em uso coletivo, para o interesse em acumular capital. Para Harvey (2013, p. 444), "a monetização das rendas feudais abre a possibilidade para o arrendamento da terra em troca de pagamentos em dinheiro, finalmente, para a compra e venda da terra como uma mercadoria. O capital de base urbana pode penetrar na zona rural e transformar as relações sociais ali". Neste sentido, o capital espalha seus tentáculos em todos os lugares viáveis a sua acumulação.

Para o capitalista, acumular será sempre o seu principal objetivo. Nesse sentido, realiza a renda da terra a partir do momento em que adquiri uma parcela de terras, obtendo, conjuntamente, todo o valor que esta possa a vir produzir e, o valor da terra mercadoria passa a ser incorporado ao seu capital.

A localização da terra tem um valor considerável no momento em que se pretende fazer alguma transação comercial envolvendo-a, logo, sendo indispensável para aqueles que enxergam na produção da cidade, a partir dos loteamentos de terras em áreas urbanas, uma oportunidade a mais para realizarem a renda fundiária urbana. No entanto, quando a terra não apresenta as

\begin{tabular}{llllll}
\hline Caminhos de Geografia & Uberlândia & v. 20, n. 72 & Dez/2019 & p. 345-359 Página 349
\end{tabular}


condições exigidas ou não é dotada de infraestrutura que possibilite maior valorização em sua área, os detentores de capital agem sobre esse espaço, transformando-o e dotando-o de fixos e fluxos que possibilitem maior extração de renda gerada por aquela parcela de terras. Logo, a localização de um loteamento pode ser primordial na absorção de maior ou menor renda da terra, pois

[...] a terra é tratada como um simples bem financeiro que é comprado e vendido segundo a renda que ele produz, como todas essas formas de capital fictício, o que é negociado é um direito sobre as receitas futuras, o que significa um direito sobre os lucros futuros do uso da terra ou, mais diretamente, um direito sobre o trabalho futuro (HARVEY, 2013, p. 448).

Assim, ao adquirir um lote o comprador adquire a concessão e o direito de poder realizar a renda capitalizada por aquela parcela de terra (OLIVEIRA, 1990), podendo vir a ganhar um adicional por sua valorização ou, a partir da implantação de bens, fixos e fluxos, dentre outros. É a renda futura gerada pela terra que o comprador paga a quem se propõe lotear a terra e a faz mercadoria. Ao adquirir a terra, simultaneamente se adquire uma renda.

Considerando os mecanismos que contribuem para que seja auferido maior ou menor valor ao solo urbano, Ribeiro (1997, p. 128-129) informa que "[...] o preço do solo urbano é um reflexo da disputa entre os agentes capitalistas para realizar o uso mais rentável da cidade. [...] o preço do solo é determinado pelo agente que puder realizar o maior faturamento com o seu uso".

O processo de parcelamento do solo urbano na forma de loteamento é a reprodução da forma no espaço; é a cidade se dinamizando, apresentando novos modos de ocupação, onde o agente capitalista consciente dessa dinâmica aproveita a aquisição de renda com a terra. Esse tipo de empreendimento, geralmente, é apresentado por seus idealizadores como um lugar novo para se construir e fixar moradia ou, como um meio para realizar um investimento financeiro e obter sobrelucros futuros.

É uma alternativa de reprodução do capital. Para Oliveira (1990, p. 73) "A renda da terra é [...] um lucro extraordinário, suplementar, permanente, que ocorre tanto no campo como na cidade. [...]. Sendo a renda da terra um lucro extraordinário permanente, ela é, portanto, produto do trabalho excedente". Independente de qualquer fator, adversidade ou benfeitoria, a terra por si só se constitui como renda para quem tem sua posse. Para Harvey (2013, p. 432) "Como a terra é monopolizável e alienável, ela pode ser arrendada ou vendida como uma mercadoria".

A terra ao ser mercadoria, quem detém o seu monopólio, direito de uso e de troca, negocia sua posse visando maior rentabilidade, mediante a venda, arrendamento ou aluguel. Assim, os loteamentos são vistos pelos donos de terras, em áreas de expansão urbana, como condição para a obtenção de um valor diferenciado a partir do desmembramento de parcelas menores, onde seu preço é determinado pelo valor de mercado e não como um produto social.

Portanto, a terra urbana se transforma em uma mercadoria como outra qualquer, passando a ter valor de uso e valor de troca. Para Barbosa (2005, p. 71) "[...], nas cidades produzidas sob a lógica do modo de produção capitalista, a terra urbana assume claramente a condição de mercadoria. [...] essencial para a realização da produção imobiliária e para a produção do espaço urbano como um todo".

Como mercadoria, a terra urbana apresenta valores diferenciados. Dependendo da área de localização de um dado terreno, este poderá apresentar maior ou menor grau de investimento e valorização. A localização é assim um fator que pode ou não trazer vantagens à área loteada.

[...] as vantagens de localização para determinados lotes de terra podem ser alteradas pela ação humana. Isso significa que a ação do próprio capital (particularmente mediante o investimento em transportes e comunicações) pode criar relações espaciais. Os atributos espaciais dos valores de uso podem então ser levados de volta ao reino da análise com qualidades socialmente criadas e, por isso, como um tema ajustado e apropriado para uma investigação plena em relação à operação da lei do valor (HARVEY, 2013, p. 400).

Os equipamentos existentes em determinados espaços, caracteriza-os e ditam as regras de como e por quem esses ambientes serão adquiridos. A terra, embora originalmente não sendo mercadoria, no modo capitalista de produção passou a ser e tem um preço a ser pago por ela, o qual concede a quem paga, o direito de fazer uso desta (OLIVEIRA, 1990), o valor quase sempre, representa aos interesses de quem tem legalmente sua posse.

$\begin{array}{lllll}\text { Caminhos de Geografia } & \text { Uberlândia } & \text { v. 20, n. } 72 & \text { Dez/2019 } & \text { p. 345-359 Página } 350\end{array}$


Para uma área ganhar maior valorização, não depende apenas de recursos naturais, pois, o trabalho humano transforma os lugares e projeta determinados meios que contribuem para que haja essa valoração num dado espaço. Assim, o Estado buscando atender a interesses de grupos específicos, dota diferentes áreas com equipamentos que atrairão pessoas que desejem ocupar suas proximidades. A procura por esses espaços gera valorização e aumento do preço da terra.

[...] duas condições são necessárias para a obtenção da renda fundiária urbana: a composição orgânica do capital investido deve ser inferior ao capital social médio e a existência da instituição jurídica da propriedade privada, [...]. Em outros termos, a propriedade privada permite a distinção entre os proprietários e os não proprietários de solo urbano e nesse caso se torna condição fundamental para que os primeiros controlem o acesso à terra e dela extraiam a renda (BARBOSA, 2005, p. 75).

Por esse prisma, para realizar a renda fundiária urbana, faz-se necessário que a quantidade de capital a ser investido em um dado espaço, deva ser menor que a receita líquida gerada nessa mesma área. Ainda, a força de trabalho empregada, o tempo a ser gasto e os recursos utilizados para que se realize a renda fundiária urbana, ao serem somados, também devem resultar em menor valor que o total da receita líquida gerada pela terra ao qual se fez a aquisição.

Como nem todos detêm a posse da terra urbana, este fator acarreta diretamente no aperfeiçoamento das desigualdades entre classes, onde quem tem a posse e o direito de realizar a renda da terra, vê seus rendimentos aumentarem com o passar do tempo. $O$ inverso também corre, pois quem não tem como realizar a renda da terra percebe o distanciamento entre os que detêm daqueles que não tem a posse da terra. Fator que contribui para que as pessoas busquem na cidade, áreas com baixa infraestrutura, muitas vezes longe das áreas centrais e de equipamentos públicos de saúde, educação, lazer, segurança, dentre outras. São as diferenças sociais convivendo em um mesmo espaço, pelo simples fato de ter ou não, jurídica e legalmente a posse da terra.

\section{A RENDA DA TERRA E SUAS PARTICULARIDADES EM CIDADES POTIGUARES}

Ao analisarmos o valor de uso e o valor de troca dado a terra, na economia capitalista, Harvey (1980) pontua seis elementos que estão intrinsecamente imbricados, devendo ser observados para que compreendamos como esses valores se concretizam no espaço urbano, considerando os equipamentos ali existentes. "O solo e suas benfeitorias são, na economia capitalista contemporânea, mercadorias. Mas, o solo e as benfeitorias não são mercadorias quaisquer [...]. Seis aspectos requerem particular atenção" (HARVEY, 1980, p.135).

(i) $\quad \mathrm{O}$ solo e as benfeitorias não podem deslocar-se livremente, e isso os diferencia de outras mercadorias, tais como trigo, automóvel e similares. O solo e as benfeitorias tem localização fixa. A localização absoluta confere privilégios de monopólio à pessoa que tem os direitos de determinar o uso nessa localização.

(ii) $\quad$ solo e as benfeitorias são mercadorias das quais nenhum individuo pode dispensar. Não posso existir sem ocupar espaço; não posso trabalhar sem ocupar um lugar e fazer uso de objetos materiais ai localizados; e não posso viver sem moradia de alguma espécie.

(iii) $O$ solo e as benfeitorias mudam de mãos relativamente com pouca frequência. [...] assumem a forma de mercadorias com muito pouca frequência mesmo que estejam constantemente em uso.

(iv) O solo é algo permanente e a probabilidade de vida das benfeitorias é muitas vezes considerável. O solo e as benfeitorias, e o direito de uso a elas ligados, por isso, propiciam a oportunidade de acumular riqueza (tanto para os indivíduos como para a sociedade). [...] O solo é peculiar em um aspecto, porque não requer ser mantido em ordem para continuar com seu potencial de uso [...].

(v) A troca no mercado ocorre em um momento do tempo, mas o uso se estende por um período de tempo. Esse aspecto da mercadoria não é peculiar apenas ao solo e às benfeitorias, mas a proporção de frequência da troca em relação à duração do uso é peculiarmente baixa. 
(vi) O solo e as benfeitorias têm usos diferentes e numerosos que não são mutuamente exclusivos para o usuário. Uma casa, por exemplo, pode ser usada simultaneamente de muitos modos diferentes (HARVEY, 1980, p.135-136).

O solo e as benfeitorias nele existentes, com suas especificidades e variáveis, apresentam condições plenas para a realização da renda da terra. Os loteamentos ao serem adequados aos padrões exigidos em legislação, sendo dotados com a infraestrutura necessária para que a terra possa ser parcelada, estão compreendidos entre os que contêm benfeitorias que valorizam seus lotes, como pode ser visto nos loteamentos Jardim Planalto, Parque Belo e Vista da Serra e, por conseguinte, contribuem para que o seu proprietário extraia maior renda da terra. Como o solo é - substrato, a base de sustentação de qualquer coisa e as benfeitorias não podem se deslocar livremente no espaço, pois são equipamentos e melhorias fixas de um dado lugar, tais como praças, estradas asfaltadas, iluminação, água, dentre outros, que geram uma valorização intrinsecamente à sua condição, o capitalista se apropria e transforma em renda (HARVEY, 1980).

O quadro a seguir retrata como os loteamentos analisados foram estruturados e equipados, visando fazer a maior extração de renda fundiária.

Quadro 1 - Infraestrutura existente nos loteamentos analisados.

\begin{tabular}{|c|c|c|c|}
\hline Cidade & $\begin{array}{c}\text { Loteament } \\
0\end{array}$ & Proprietário & Infraestrutura \\
\hline $\begin{array}{l}\text { Boa } \\
\text { Saúde }\end{array}$ & $\begin{array}{c}\text { Parque } \\
\text { Belo }\end{array}$ & LL Imóveis & $\begin{array}{c}\text { Água, energia elétrica, meio fio, } \\
\text { área non aedificandi, área } \\
\text { institucional. }\end{array}$ \\
\hline $\begin{array}{l}\text { Lagoa } \\
\text { Salgad } \\
\quad \mathrm{a}\end{array}$ & $\begin{array}{l}\text { Jardim } \\
\text { Planalto }\end{array}$ & Cabral Imóveis & $\begin{array}{l}\text { Água, energia elétrica, meio fio, } \\
\text { praça, playground, área non } \\
\text { aedificandi, área institucional, ruas } \\
\text { identificadas e acesso para as } \\
\text { principais vias da cidade. }\end{array}$ \\
\hline $\begin{array}{c}\text { Serra } \\
\text { Caiada }\end{array}$ & $\begin{array}{c}\text { Vista da } \\
\text { Serra }\end{array}$ & $\begin{array}{c}\text { Vista } \\
\text { Empreendimento } \\
\mathrm{s}\end{array}$ & $\begin{array}{l}\text { Água, energia elétrica, meio fio, } \\
\text { área non aedificandi, área } \\
\text { institucional, e acesso para as } \\
\text { principais vias da cidade. }\end{array}$ \\
\hline
\end{tabular}

Fonte: Cabral Imóveis; LL imóveis e Rio Norte Imobiliária, 2015. (Adaptado por MOURA, 2018).

Com relação ao parcelamento de terras nos municípios de Boa saúde, Lagoa Salga e Serra Caiada, alguns loteamentos localizam-se no perímetro urbano e outros dentro da área considerada de expansão urbana.

Os loteamentos de Boa Saúde podem ser considerados bem localizados, pois, quando não estão às margens de alguma rodovia, seu acesso é fácil. Os referidos loteamentos, ao serem idealizados, os empreendedores dotaram a área de meio fio, rede elétrica, vias de ligação com os principais acessos à cidade, conforme pode ser visualizado no (Mapa 2).

Em Lagoa Salgada, a empresa que projetou os principais loteamentos, apresentou maior rigor, além de dotar a área de meio fio e rede elétrica, nomeou as ruas, construiu praças, e playgrounds e instalou equipamentos para a prática de atividades físicas (Mapa 3). 


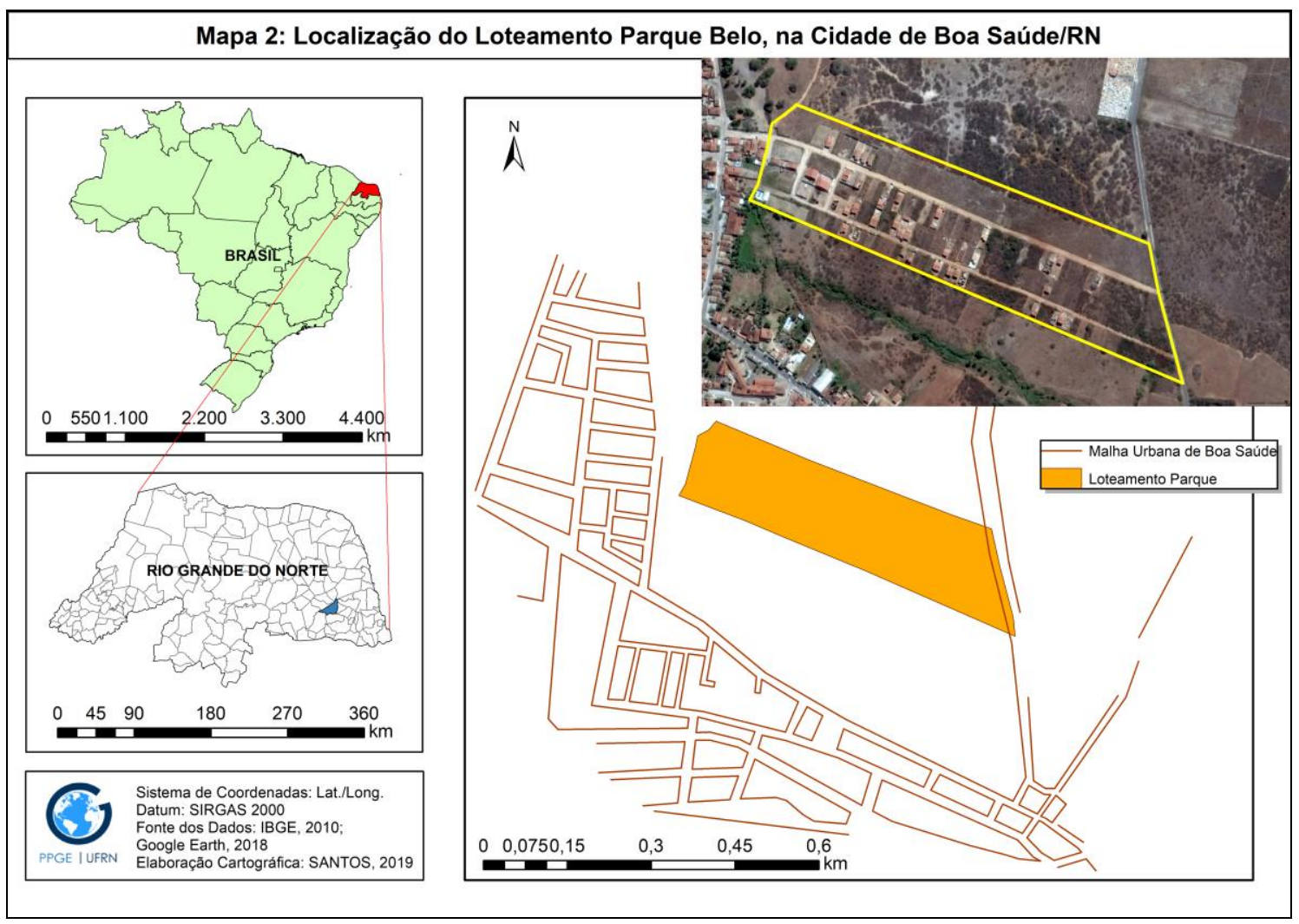

Fonte: IBGE (2010); Google Earth (2018).

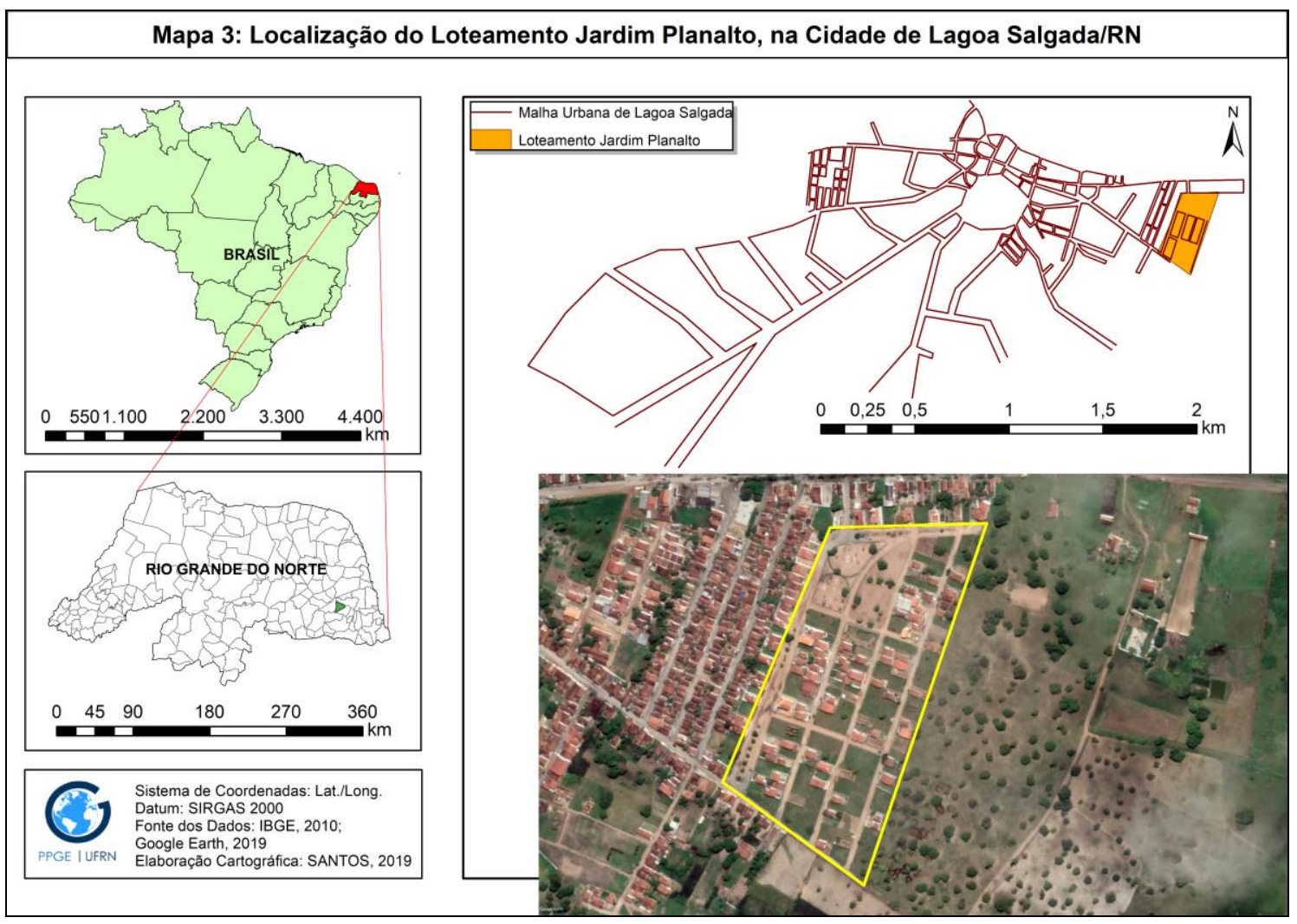

Fonte: IBGE (2010); Google Earth (2019). 
Em Serra Caiada, por sua vez, além dos serviços de infraestrutura oferecidos, os loteamentos estão localizados em posições estratégicas. O loteamento Vista da Serra está localizado às margens da BR 226 que liga a capital do estado e as regiões do Seridó e Alto Oeste, além de estar às margens de uma das principais entradas da cidade. Outro loteamento, o Mirante da Serra, localiza-se na via que dá acesso ao principal cartão postal da cidade, a formação rochosa denominada "Serra Caiada" (Mapa 4).

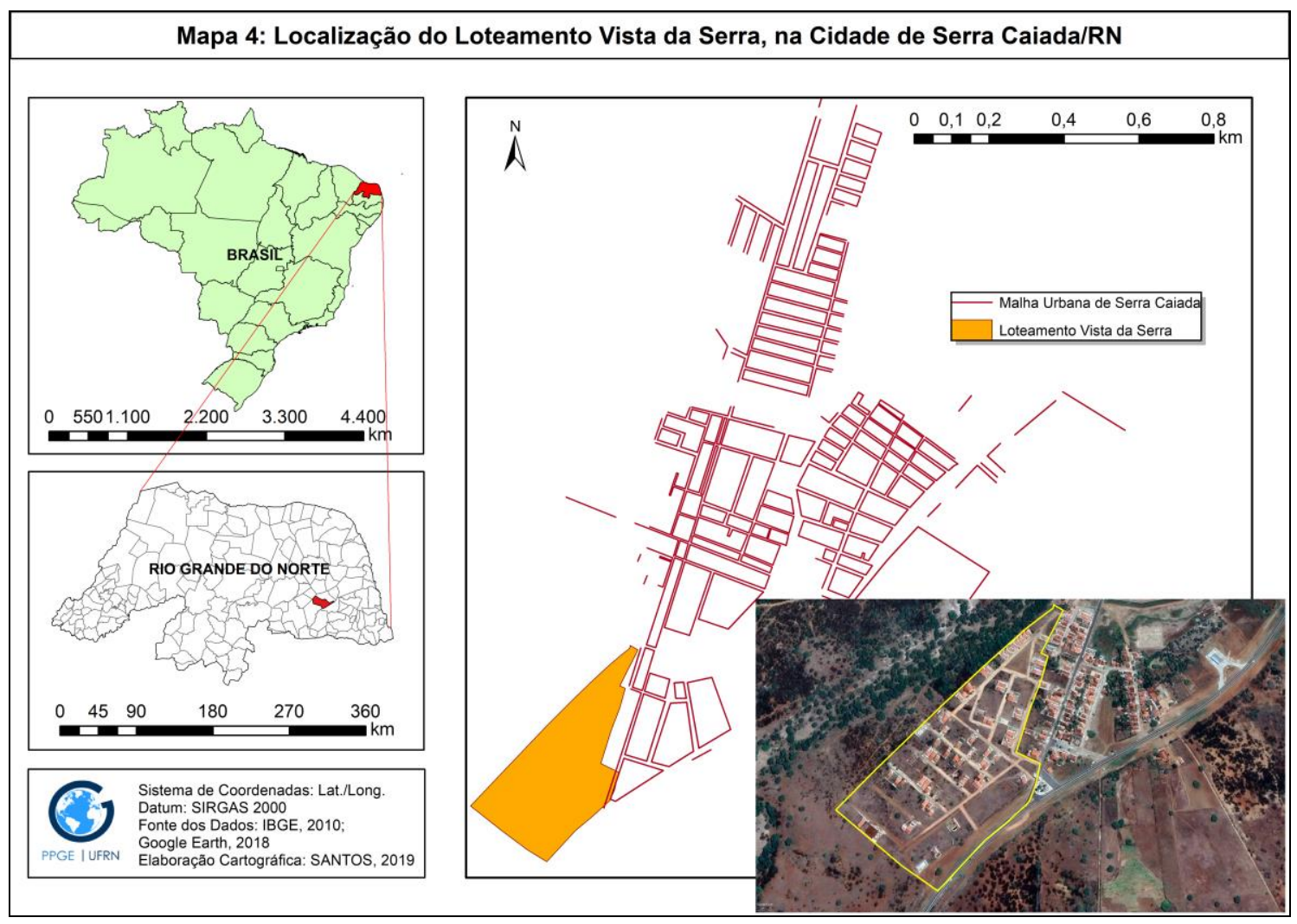

Fonte: IBGE (2010); Google Earth (2018).

Percebemos, portanto, que os loteamentos estudados nesses municípios estão estruturados com benfeitorias que contribuem para a valorização da terra sendo esta transformada em mercadoria.

Sendo a terra uma mercadoria, a compra desta assegura ao adquirente o direito de realizar a renda por ela auferida. Nessa condição, a renda aparece na contabilidade de quem a adquiriu como o juro sobre o dinheiro investido na compra da terra. O dinheiro ao ser investido com a compra da terra transforma-se em capital que rende juros futuros ao proprietário.

Assim, a terra é um capital fictício, uma vez que o direito de uso conquistado juridicamente pela sua compra consolida-se como mercadoria que gera sobrelucro para quem a detém. Ao negociar a compra da terra, como capital fictício, o que é comercializado é o direito sobre os ganhos futuros gerados a partir do uso da terra ou, mais diretamente, um direito sobre os trabalhos que se realizarão na terra adquirida (HARVEY, 2013).

Quem compra terra em área urbana, está legalmente adquirindo o direito de poder fazer uso dessa fração, como também, se beneficiar com a renda decorrente do trabalho nela realizado. Quando uma incorporadora ou agente particular resolve investir em um dado espaço da cidade, está vislumbrando ganhos futuros gerados pelo seu investimento. Considerando a teoria da renda, discutida por Marx, para explicar como a renda se realiza na área urbana, demos ênfase a três tipos de rendas geradas em decorrência do uso dado a terra: a renda absoluta, a renda de monopólio e a renda diferencial.

Como o solo é uma mercadoria monopolizável e não reproduzível, [...] por deter o monopólio do controle da terra, o proprietário tem total poder de decisão de colocar ou não seu terreno à disposição para o aluguel ou arrendamento, com vistas à

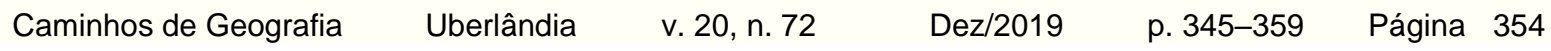


obtenção de renda absoluta. Ou seja, uma das formas de realização desta modalidade de renda se dá a partir da concessão, por parte do proprietário, do acesso e direito de uso do solo urbano a outrem mediante o pagamento do aluguel (BARBOSA, 2005, p. 75).

A partir do momento em que o solo deixa de ter como função o valor de uso, também, passando a acumular para seu detentor, o valor de troca, quem detém o seu domínio, não usufrui apenas de sua posse, mas do direito de poder fazer uso da renda por ele produzida. Logo, o dono da terra urbana tanto pode fazer concessões como também alugar a parcela de terra que tem sobre sua tutela a outrem e, o excedente gerado e pago por tal ação ao proprietário se concretizará como sendo a renda absoluta, uma vez que, para a aquisição dessa renda não se fez necessário à materialização de nenhum tipo de trabalho social.

[...] o aspecto central que funda a renda absoluta é a capacidade inerente à propriedade privada da terra de gerar renda para o proprietário. Dessa maneira, a renda absoluta configura uma determinação da propriedade privada, ou seja, o desaparecimento desta instituição jurídica resultaria na impossibilidade de extração de renda absoluta (BARBOSA, 2005, p. 75).

A renda absoluta se realiza, antes de qualquer coisa, pela condição em que ela se encontra, ou seja, a terra transformada em mercadoria, um bem privado que para se ter acesso e fazer uso de uma porção, faz-se necessário o trabalho que se materializa em capital. Pelo fato da terra ser privada, o seu proprietário ao colocá-la no mercado para a venda em loteamentos, presume-se uma maneira para realizar a renda absoluta, pois, por ser o detentor do direito de uso e de troca, toda renda subtraída com a venda dos lotes, se transforma em capital para o seu dono.

As outras formas de realização da renda da terra, também se fazem presentes na realidade urbana de Boa Saúde, Lagoa Salgada e Serra Caiada; no mercado de terras existentes por meio de loteamentos em áreas de expansão. Ao considerarmos o processo de desencadeamento do parcelamento do solo, constata-se que a realização da renda diferencial é a mais observada tendo em vista as particularidades existentes em cada loteamento.

Compõem essas particularidades: lotes legalizados, formas de negociação; qualidade dos empreendimentos; propaganda no período da venda; localizações estratégicas, como os principais pontos de acesso à cidade; proposta de ser um lugar diferenciado para o comprador que já adquire o lote com a infraestrutura necessária à sua ocupação como água encanada e iluminação pública. Estes itens contribuem para que a renda diferencial se concretize tanto na área urbana, como em áreas de expansão urbana.

A renda diferencial é o componente da renda fundiária que se baseia nas diferenças entre as condições físicas e localizações dos terrenos e nos diferenciais de investimentos sobre eles, ou no seu entorno, aplicados. Este componente se soma à renda absoluta, que é, propriamente, a remuneração paga pela existência da propriedade privada (BONDUKI \& ROLNIK, 1979, p. 147).

Seguindo o exposto, a renda diferencial pode ser condicionada a fatores diversos, tais como: localização, proximidade a determinados recursos naturais e, qualidade do solo ou a equipamentos públicos e de infraestrutura fixados, tanto pela iniciativa pública como privada; através de ações realizadas pelos próprios donos de terrenos que ao pensarem na obtenção de sobrelucros, dota-os com estradas, redes de água, energia e até pavimentação. Como a terra é privada e já existe a possibilidade para o dono realizar a renda absoluta por já deter o direito de uso e de troca, ao ser dotado com algo que o diferencie das demais, faz com que o valor a ser pago pelo direito de uso de uma parcela dessa terra seja superior a outras áreas, onde tais benfeitorias físicas estejam ausentes ou estejam mal localizadas.

Os loteamentos regulares, ao serem colocados à venda, contam com infraestrutura e maior proximidade com os equipamentos públicos existentes na cidade, possibilitando ao comprador fazer melhor uso do lote. Nesse contexto, o valor a ser pago pelo lote é bem maior que o que se pagaria para adquirir um lote distante do centro, de difícil acesso e com ausência de infraestrutura. São essas peculiaridades existentes no espaço que contribuem para que se realize a renda diferencial. Observamos que a conexão dos loteamentos com o restante da área urbana se dá pelas principais vias de acesso, quando se não, estão localizados às margens dessas vias, tanto por quem chega à cidade, como por quem trafega por suas ruas.

No entanto, existem fatores de ordem natural que, também, contribuem para que a renda diferencial seja realizada pelo proprietário da terra.

$\begin{array}{llllll}\text { Caminhos de Geografia } & \text { Uberlândia } & \text { v. 20, n. } 72 & \text { Dez/2019 } & \text { p. 345-359 Página } 355\end{array}$


Em todo lugar em que há renda, a renda diferencial produz-se e obedece às mesmas leis que a renda diferencial agrícola. Em todo lugar em que forças naturais podem ser monopolizadas e assegurar ao industrial que as emprega um sobrelucro, quer estas forças naturais sejam uma queda d'água, uma mina rica em minérios, uma água abundante em peixes, um bom terreno para construções, o indivíduo que tem a propriedade arrebata ao explorador o sobrelucro, sob a forma de renda (MARX, 1982, p. 388).

Seguindo o raciocínio de Marx (1982), o proprietário da terra que conta com algum dos itens elencados, já realiza a renda diferencial, vez que só a porção de terra a que lhes pertence conta com determinada especificidade em relação a terras vizinhas. Esse diferencial é o elemento motivador para que haja maior valorização da área no momento em que se pretenda colocá-la no mercado para venda. Entretanto, em terras de áreas urbanas difere da terra agrícola no tocante à renda diferencial.

$\mathrm{Na}$ terra agrícola, os recursos naturais são de fundamental importância. Não que tais recursos sejam menos importantes para a área urbana, mas, nesse caso em particular, a valorização se dá pela proximidade a equipamentos que valorizam a área onde estão localizados e elevam o preço da terra em seu entorno, tais como: shopping centers, redes de lojas e supermercados, equipamentos escolares e universidades, equipamentos de saúde e segurança, áreas de lazer e esportes, condomínios residenciais de alto padrão e ruas asfaltadas.

[...] o preço da terra é gerado pela apropriação da terra em conjunto com os elementos presentes na forma urbana, que estão em constante transformação. Este fato está intimamente ligado à lógica de compreender que os agentes responsáveis por orquestrar tais mudanças são os mesmos que indicam a direção da expansão do tecido urbano e os preços dos terrenos em cada porção da cidade considerando o entorno imediato e as distâncias em relação aos principais equipamentos urbanos (NASCIMENTO, 2014, p. 104).

Cada cidade tem suas singularidades e agentes determinantes que atuam diretamente no preço da terra, provocando a diferenciação de áreas dentro de uma mesma cidade. Assim, as cidades do interior potiguar, mesmo não contando com equipamentos nas mesmas proporções dos que existem nos grandes centros urbanos, como grandes empreendimentos imobiliários, universidades, sistemas de transportes, dentre outros, apresentam fatores que contribuem para que a renda diferencial se efetue.

Ainda que de maneira incipiente e alcance local, a renda diferencial se realiza e se beneficia a partir de fatores como: características dos moradores do bairro; segmento social dos que ocupam determinada área; proximidade com o centro da cidade e, por conseguinte da área comercial. O solo urbano na área comercial de uma cidade, quase sempre é o local onde se fixa o preço mais elevado a ser pago por uma parcela de terra, tendo em vista que em muitos desses centros urbanos a atividade comercial se configura como fonte de ocupação e renda para os moradores.

Analisando as características apresentadas, teremos uma transição entre duas categorias de renda. Tentando entender como ocorre a renda da terra no solo urbano, passaremos da renda diferencial para a renda de monopólio. Para compreender como ocorre a renda de monopólio e suas características na terra urbana, partiremos de Spósito (1991) quando diz que

A realização da renda de monopólio na cidade é sempre expressão de um dado momento histórico, visto que as características que permitem sua realização em determinado terreno não são naturais (como as que determinam a renda agrícola de monopólio), mas historicamente determinadas. E no processo social e histórico de produção da cidade que certas localizações se configuram, em dado momento, como especiais e únicas no que se refere à possibilidade de incorporar um determinado tipo de produção imobiliária (SPÓSITO, 1991, p. 178).

A renda fundiária urbana independe de ter ou não a presença de recursos naturais. Passa, principalmente, pelo fator econômico e social, pois, dependendo da classe social que ocupe uma determinada área na cidade, a referida área poderá sofrer maior valorização ou ser considerada uma área problemática, provocando sua desvalorização. No tocante aos loteamentos, a renda de monopólio não é expressiva como a renda diferencial, uma vez que, o monopólio se dá pela exclusividade, ter para si o controle de alguma coisa, algo que só existe em uma determinada área, com qualidades e especificidades intrínsecas ao local, o que não se verifica em nossa área de estudo.

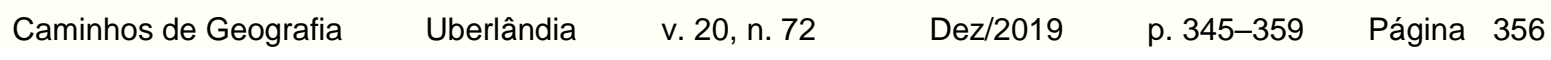


Assim, quando uma incorporadora ou um particular resolve cercar uma gleba de terras e vendê-la na forma de loteamento em um condomínio fechado, tendo como principal moeda de troca, fatores como segurança, localização, infraestrutura e a unicidade daquele loteamento, chegar-se-á a uma aproximação de como se realiza a renda de monopólio.

Uma área que conta com transporte público de qualidade, é bem servida com redes de energia elétrica, água encanada, saneamento básico, áreas destinadas para a prática de esportes e lazer, possibilita que o detentor de terras urbanas possa realizar a renda de monopólio. Na cidade, a terra é um produto escasso, caro e de difícil acesso, para alguns, pelo preço que é cobrado. Quem a detém mantém para si o monopólio desse produto. Fazemos a ressalva que a terra se torna um produto escasso, mesmo em áreas urbanas, apenas para quem não dispõem de uma boa reserva financeira (dinheiro). De acordo com Singer (1979), a renda de monopólio

[...] decorre da existência de localizações que conferem aos que as ocupam o monopólio do fornecimento de determinadas mercadorias. É o caso, por exemplo, de bares e restaurantes localizados em escolas, clubes, estádios de esportes, aeroportos e semelhantes, afastados de outros estabelecimentos congêneres, que por isso dispõem de um público "cativo". [...], os que dispõem do monopólio, graças à localização, podem cobrar preços mais elevados pelos produtos que vendem, o que dá lugar a uma renda de monopólio que é em geral, apropriada no todo ou em parte pelo proprietário do imóvel (SINGER, 1979, p. 26).

$\mathrm{O}$ fato de um cidadão ser detentor de determinado equipamento que the confere o direito de realizar a renda pela exclusividade do equipamento que o diferencia dos demais, possibilita a aferição da renda de monopólio. Assim, o local físico onde se localiza determinada cadeia de restaurantes; locais seletos com público cativo; produtos específicos que o fazem ser singular, diferente dos demais, também contribui para que seja realizada a referida renda.

O espaço da cidade favorece o desenvolvimento das diferentes rendas no que concerne à produção fundiária, pois a cidade é um produto, a terra não o é, mas, fora transformada em produto a partir do momento em que o seu acesso só seria possível mediante pagamento, troca por dinheiro.

A produção de espaço urbano geralmente ocorre pela anexação à cidade de áreas que até então eram usadas por atividades agrícolas. O valor de sua produção é igual à renda (agrícola) da terra que se deixa auferir. Considerando que a demanda por terra em área urbana muda constantemente, em virtude do próprio processo de apropriação e ocupação do espaço pela ampliação do tecido urbano, o valor a se pagar por uma determinada área deste espaço pode sofrer oscilações e diferenças de preço, provocando a especulação imobiliária.

Quando os atores envolvidos com o mercado imobiliário resolvem agregar determinada área ao espaço urbano, projeta um preço futuro a se cobrar pela terra que será anexada à cidade. Logo, temse uma antecipação da valorização daquela terra prevendo as mudanças e a implantação de infraestrutura pelo Estado ou por particulares, motivos pelos quais, os especuladores que lucram com a venda da terra resolvem esperar para que haja uma maior valorização da área para só depois colocar a terra à venda no mercado (SINGER, 1979).

\section{CONSIDERAÇÕES FINAIS}

Ao analisarmos a trajetória que desencadeou na terra como produto, a menos de dois séculos, o valor da terra era voltado para sua função social enquanto receptáculo e substrato do homem. Com a nova nomenclatura dada por força de lei que a transforma em um produto passível de troca, a terra perde sua identidade primeira e porque não, junto com essa legislação, sua função social fora amortizada. Nesse contexto, seu acesso tem se tornado cada vez mais difícil por uma parcela bastante significativa de brasileiros que a cada dia vê a possibilidade de se tornar dono de um pedaço de terra, mais distante de sua realidade.

Ao considerarmos as desigualdades sociais que se mantém ao longo da história, mesmo com a crescente oferta de terras parceladas, percebemos que essa oferta não atende aos segmentos mais pobres, haja vista que esse segmento social não dispõem de uma renda que seja suficiente para manter suas necessidades primeiras e, poder pagar por uma parcela de um lote de terras. Logo, o mercado de terras visa não menos que a maior extração de renda possível, possibilitada pelo fracionamento da terra ao ser colocada no mercado sob a forma de lotes. Neste sentido, a renda da terra é subtraída de acordo com os interesses de quem a coloca no mercado. Vale salientar que, a

$\begin{array}{lllll}\text { Caminhos de Geografia } & \text { Uberlândia } & \text { v. 20, n. } 72 & \text { Dez/2019 } & \text { p. 345-359 Página } 357\end{array}$


terra é um produto natural que não é capaz de ser criado ou refeito e, quem tem sua posse, tem para si o domínio e o "direito" de também explorá-la e dar o uso mais rentável para o seu proprietário.

É fato que as desigualdades em decorrência de ter ou não a posse de terra, vem aumentado. No entanto, essas desigualdades merecem uma análise mais aprofundada, vez que a função social da terra não pode deixar de existir em prol de interesses meramente mercantilistas, onde os beneficiados compreendem uma pequena parcela da sociedade. Fazemos a ressalva que, ao dotar determinadas áreas com infraestrutura, vias de acesso e equipamentos, o próprio Estado contribui de maneira eficaz no que diz respeito à subtração da renda da terra e age de maneira perversa para aumentar as desigualdades e diferenças entre quem é detentor ou não de uma parcela de terras no Brasil.

Os resultados do estudo realizado nos municípios de Boa Saúde, Lagoa Salgada e Serra Caiada, confirmam o que está colocado no segundo parágrafo dessas considerações, nos levando a concluir que, por um lado, a terra urbana nesses municípios ganha um valor proeminente quando esta é parcelada, contribuindo para que os agentes imobiliários aufira lucros consideráveis, sendo, portanto, um bom negócio o comércio de terras para o setor imobiliário. Por outro lado, o lote de terra oferecido, tem um preço que atende aos interesses da população solvável, ou seja, aquela que pode pagar pelo lote e pelas benfeitorias, deixando de lado os segmentos mais pobres que, em sua maioria, necessitam da terra para construir a sua moradia, uma vez que as condições socioeconômicas não lhe permitem fazer aquisição de um lote terras para que possa, assim, fixar-se na cidade.

\section{REFERÊNCIAS}

BARBOSA, Adauto Gomes. Produção do espaço e transformações urbanas no litoral sul de João Pessoa - PB. 2005. 192f. Dissertação (Mestrado em Geografia). Centro de Ciências Humanas, Letras e Artes/ Universidade Federal do Rio Grande do Norte, Natal, 2005.

BONDUKI, Nabil; ROLNIK, Raquel. Periferia da grande São Paulo: reprodução do espaço como expediente de reprodução da força de trabalho. In: MARICATO, Ermínia. A produção capitalista da casa (e da cidade) no Brasil industrial. São Paulo: Editora Alfa-Omega, 1979.

BRASIL. Lei no 6.766/1979. Presidência da República. Brasília. 1979.

. Dispõe sobre o parcelamento do solo urbano e dá outras providências. Brasília, 1979.

CARLOS, Ana Fani Alessandri. A (Re) produção do espaço urbano. São Paulo: Universidade de São Paulo, 1994b.

HARVEY, David. A justiça social e a cidade. São Paulo: Hucitec, 1980.

Os limites do capital. São Paulo: Boitempo, 2013.

MARICATO, E. Brasil, cidades: alternativas para a crise urbana. 5. ed. Petrópolis: Vozes, 2001.

MARTINS, José de Souza. O cativeiro da terra. São Paulo: LECH - USP, 1979.

MARX, Karl. O capital. Edição resumida, 7. ed. Rio de Janeiro: Zahar Editores, 1982.

MOURA, Francisco Aracildo de. Loteamentos em pequenas cidades: um estudo do parcelamento do solo em Lagoa Salgada - RN. Monografia. Universidade federal do Rio Grande do Norte/Centro de Ciências Humanas, Letras e Artes, Natal, 2014.

Parcelamento de terras e expansão urbana na microrregião do agreste potiguar: loteamentos e especulação imobiliária em Boa Saúde, Lagoa Salgada e Serra Caiada/RN. Dissertação (Mestrado em Geografia), Universidade federal do Rio Grande do Norte/Centro de Ciências Humanas, Letras e Artes, Natal, 2016. $116 \mathrm{f}$.

NASCIMENTO, Agnaldo da Silva. No vazio, caberiam casas, parques, fábricas... caberia muita cidade. 2014. Dissertação (Mestrado em Geografia), Presidente Prudente, Universidade Estadual Paulista/Faculdade de Ciência e Tecnologia, Presidente Prudente, 2014. 142 f.

OLIVEIRA, Ariovaldo Umbelino de. Modo capitalista de produção e agricultura. 3.ed. São Paulo: Atica1990 (Série Princípios). 
RIBEIRO, Luiz Cesar de Queiroz. Dos cortiços aos condomínios fechados: as formas de produção de moradia na cidade do Rio de Janeiro. Rio de Janeiro: Rio de Janeiro: Civilização Brasileira, 1997.

SINGER, Paul. O uso do solo urbano na economia capitalista. In: MARICATO, Ermínia. A produção capitalista da casa (e da cidade) no Brasil industrial. São Paulo: Editora Alfa-Omega. 1979.

SILVA, Miquéias Rildo da. Elaboração cartográfica: Mapa da área de estudo (Boa Saúde, Lagoa Salgada e Serra Caiada/RN). 2018.

SPOSITO, Maria da Encarnação Beltrão. $O$ chão arranha o céu: a lógica da reprodução monopolista da cidade. (Tese de Doutorado) - Universidade de São Paulo. São Paulo, 1991.

Recebido em: 13/11/2018

Aceito para publicação em: 21/10/2019 